\title{
Association of depression with evolution of heart failure in patients with type 2 diabetes mellitus
}

Ying Wang ${ }^{1}$, Hong Yang ${ }^{1}$, Mark Nolan ${ }^{1}$, John Burgess ${ }^{2}$, Kazuaki Negishi ${ }^{1}$ and Thomas H. Marwick ${ }^{1,3^{*}}$ (D)

\begin{abstract}
Background: Depression is a prevalent, independent predictor of mortality in patients with heart failure (HF). Depression is also common in type 2 diabetes mellitus (T2DM), which is itself an important risk factor for HF. However, association of depression with incident HF in T2DM is undefined. The aim of the present study was to evaluate the predictive value of depression in predicting incident $\mathrm{HF}$ in a community-based cohort of asymptomatic patients with T2DM.

Methods: We prospectively recruited 274 asymptomatic T2DM patients $\geq 65$ years (age $71 \pm 4$ year, 56\% men) with preserved EF and no ischemic heart disease from a community-based population. The Patient Health Questionnaire 9 (PHQ-9) was used to detect depression, and LV dysfunction was sought with a comprehensive echocardiogram, including LV hypertrophy (LVH) and subclinical diastolic function (E/e'). Over a median follow-up of 1.5 years (range 0.5-3), 20 patients were lost to follow-up and 254 individuals were followed for outcomes.

Results: At baseline, depression was present in 9.5\%, LVH was identified in 26\% and reduced E/e' in 11\%. Over a median follow-up of 1.5 years, 37 of 245 patients developed new-onset HF and 3 died, giving an event rate of 107/1000 person-years. In a competing-risks regression analysis, depression (adjusted HR 2.54, 95\% Cl 1.18-5.46; $\mathrm{p}=0.017$ ) was associated with incident HF and had incremental predictive power to clinical, biochemical and echocardiographic variables.
\end{abstract}

Conclusion: Depression is prevalent in asymptomatic elderly patients with T2DM, and depression independently and incrementally predicts incident HF.

Keywords: Depression, Incident heart failure, Type 2 diabetes mellitus

\section{Background}

Heart failure (HF) has been recognized as one of the most common and malignant complications of type 2 diabetes mellitus (T2DM) [1]. HF has been reported in $>22 \%$ elderly patients with diabetes, and the HF incidence rate was 12.6 per 100 person-years [2]. Among elderly patients with DM, the 5-year mortality rate was approximately ninefold higher in those who developed HF than in those who did not [2]. Depressive symptoms

\footnotetext{
*Correspondence: Tom.Marwick@bakeridi.edu.au

${ }^{3}$ Baker Heart and Diabetes Institute, 75 Commercial Road, Melbourne,

VIC 3004, Australia

Full list of author information is available at the end of the article
}

are common in the community, but the $19 \%$ prevalence of depression in patients with T2DM is about double that of those without DM [3]. In patients with existing HF, comorbid depression and diabetes are associated with a higher mortality and rehospitalisation rate [4]. The presence of depression more than doubled the risk of allcause of mortality in HF (hazard ratio [HR] 2.29; 95\% CI 0.94-5.40; $\mathrm{p}=0.05$ ), and both DM and depression led to a nearly fourfold increment in all-cause mortality (HR 3.71; 95\% CI 1.49-9.25; $\mathrm{p}=0.005$ ) [4].

Depression is an independent predictor of HF onset in elderly patients with isolated systolic hypertension, which is independent of demographic characteristics, medical history and myocardial infarction risks [5]. Although 
prior studies have found the association of depression and adverse outcomes with diabetes alone or heart failure alone, the association of depression with incident HF in patients with diabetes is unclear, especially as death is a competing risk. The current study was undertaken to evaluate the extent to which level of depression is able to identify risk of incident HF in in a community-based cohort of asymptomatic patients with T2DM.

\section{Methods}

\section{Study population}

We prospectively recruited 274 asymptomatic T2DM patients aged $\geq 65$ with preserved LVEF from a community-based population in Australia. Patients with existing HF or known ischemic heart disease (reported with coronary artery disease including CABG and/or myocardial infarction with regional scar) were excluded, as were patients with more than moderate valve disease, history of HF, LVEF $<40 \%$, or inability to acquire adequate echocardiographic images for baseline analysis.

\section{Ethics, consent and permissions}

All participants provided written, informed consent, and the study protocol was approved by the Tasmanian Human Research Ethics Committee.

\section{Clinical features}

T2DM was based on self-report of this diagnosis including the use of relevant medication. Obesity was defined as body mass index (BMI) $\geq 30 \mathrm{~kg} / \mathrm{m}^{2}$. Demographics, disease and family history and medication use were obtained using a standardized questionnaire. BMI was calculated as weight in kilograms divided by height in meters squared. In addition to standardized weight and height measurements, waist circumference (WC) at the midpoint between the lower costal margin and the iliac crest was measured to the nearest millimeter by a trained examiner. After at least 10 min rest in a quiet room, supine resting blood pressure (BP) was measured twice and averaged in each patient. Active hypertension was defined by a mean systolic blood pressure $(\mathrm{BP}) \geq 140 \mathrm{mmHg}$ or a diastolic $\mathrm{BP} \geq 90 \mathrm{mmHg}$ [6]. International Federation of Clinical Chemistry (IFCC) standardized hemoglobin A1c (cutoff $64 \mathrm{mmol} / \mathrm{mol}$ ), fasting glucose, creatinine and estimated glomerular filtration rate (eGFR) were extracted from pathology records. To estimate missing values for $\mathrm{HbA1c}$, we carried out imputation using linear regression equation.

\section{Depression assessment}

All participants completed the Patient Health Questionnaire 9 (PHQ-9) at baseline assessment. Each item in the PHQ-9 questionnaire corresponds to one of the nine
DSM-IV criteria for diagnosis of major depression, and respondents indicate their level of agreement with each item $(0=$ not at all, $1=$ several days, $2=$ more than half of the days, $3=$ nearly every day). The validated cutoff PHQ-9 score $\geq 10$ was used as diagnosis for the presence of depression [7], and further stratified respondents into four categories of depressive symptomatology based on the total PHQ-9 score: minimal (0-4), mild (5-9), moderate $(10-20)$, and severe $(\geq 20)$.

\section{Echocardiography}

A comprehensive echocardiogram including standard transthoracic 2D and Doppler echocardiography was performed using the same ultrasound machine (Siemens ACUSON SC2000, 4V1c and 4Z1c probes, Siemens Healthcare, Mountain View, CA) in accordance with the American Society of Echocardiography guidelines [8, 9]. Images were saved in raw data format and analyzed offline. LV internal dimensions and wall thickness, chamber volumes and valvular morphology were assessed. LV mass index (LVMi) was obtained from LV mass measurement using standard criteria and normalized for body size (body surface area or height to the power of 1.7). LV hypertrophy (LVH) was defined as LVMi (normalized for body surface area) $>115 \mathrm{~g} / \mathrm{m}^{2}$ for males and $>95 \mathrm{~g} /$ $\mathrm{m}^{2}$ for females. LVEF was measured using the modified Simpson's biplane method. LV inflow was obtained using pulsed wave Doppler in the apical 4-chamber view; peak early (E) and late (A) diastolic velocities, deceleration time and E/A ratio were assessed. Peak early diastolic medial and lateral mitral annular velocity $\left(\mathrm{e}^{\prime}\right)$ and the ratio of mitral inflow early diastolic velocity to average $\mathrm{e}^{\prime}$ velocity were obtained from pulsed tissue Doppler; $\mathrm{E} / \mathrm{e}^{\prime}>13$ was used as an indicator of diastolic dysfunction [10].

\section{Outcomes}

The primary endpoint was new-onset of HF, and all-cause mortality was considered as a competing risk. Potential HF symptoms were assessed through regular follow-up phone calls, followed by symptom surveillance questionnaires, clinical visits and repeated echocardiography. Records of all-cause hospitalization and mortality were obtained from administrative data. The diagnosis of HF was established according to Framingham HF criteria; symptoms and physical signs that were suspicious for HF were reviewed by three independent cardiologists [11].

\section{Statistical analysis}

Descriptive data are presented as mean \pm standard deviation (SD) and dichotomous data as subject number and percentage. Comparisons between the groups were performed by independent samples $t$ test; the 
Kruskal-Wallis test was used for comparison of non-normally distributed variables. Univariable and multivariable stepwise forward linear regression were performed in order to identify the variables with significant association with PHQ-9 score.

Univariable Cox regression was used to identify the predictors of incident HF among clinical, demographic and echocardiographic variables. We fitted a competingrisk model to compute hazard ratio (HR) and $95 \%$ confidence interval $(95 \% \mathrm{CI})$ for the associations between each risk factor and incident HF [12]. A multivariable model was constructed to determine the independent predictors, guided by univariable analyses and the clinical relevance of the variables. Competing risk methods were used to account for the competing risk of death when analyzing the endpoint of time to HF. The cumulative incidences of HF were calculated and graphically displayed separately for patients with and without depression. Gray's K-sample test was to compare the cumulative incidence estimates of HF between patients with/without depression [13], which accounts for all-cause of death as a competing risk of HF. All data were analyzed using standard statistical computer software (SPSS 22, IBM, Chicago, IL and Stata, V.12.0, StataCorp, College Station, Texas, USA); $\mathrm{p}<0.05$ was deemed to be statistically significant.

\section{Results}

\section{Patient characteristics}

Table 1 describes the clinical, echocardiographic and biochemical features of 274 asymptomatic T2DM patients $\geq 65$ years old with preserved EF from the community who were prospectively recruited and underwent baseline tests. Table 1 also includes the 254 T2DM participants who were included in the final analysis (see below). In the total recruited group of 274 subjects, the prevalence of LV dysfunction was 13\% (by LVH) and $11 \%$ (by abnormal E/e' cutoff 13 ). In the 254 subjects included in the final analysis, baseline HbA1c was available in 196 individuals (age $71 \pm 4$ years, $55 \%$ men). In this subgroup, the baseline HbA1c was $53.2 \pm 11.4 \mathrm{mmol} / \mathrm{mol}$. After imputation of missing values, the baseline $\mathrm{HbAlc}$ was $53.5 \pm 10.1 \mathrm{mmol} / \mathrm{mol}$ (Table 1 ).

\section{Depression}

Based on PHQ-9 score, 37 (14\%) patients had minimalto-mild depressive symptoms (PHQ-9 score 5-9), and $25(9 \%)$ patients were identified as having moderate-tosevere depressive symptoms (PHQ-9 score 10-20), and 2 $(0.7 \%)$ patients were identified as having severe depressive symptoms (PHQ-9 score $\geq 20$ ), and were diagnosed as having depression using the cutoff of PHQ-9 score $\geq 10$. Table 2 shows the features associated with
Table 1 Baseline characteristics (demographic, clinical, echocardiographic, physiologic) of $\mathbf{2 7 4}$ elderly asymptomatic patients with T2DM

\begin{tabular}{|c|c|}
\hline \multicolumn{2}{|l|}{ Demographic and clinical characteristics } \\
\hline Age (years) & $71 \pm 4.4$ \\
\hline Male gender $(n, \%)$ & $150(54.7)$ \\
\hline Weight (kg) & $85.8 \pm 17.2$ \\
\hline Height (cm) & $168.4 \pm 10.0$ \\
\hline $\mathrm{BMI}\left(\mathrm{kg} / \mathrm{m}^{2}\right)$ & $30.3 \pm 5.9$ \\
\hline Waist circumference (cm) & $103.2 \pm 13.3$ \\
\hline Obesity $(n, \%)$ & $135(49.3)$ \\
\hline Heart rate (n/min) & $69 \pm 11$ \\
\hline Systolic blood pressure (mmHg) & $139 \pm 15$ \\
\hline Diastolic blood pressure $(\mathrm{mmHg})$ & $81 \pm 10$ \\
\hline Hypertension $(n, \%)$ & $204(74.4)$ \\
\hline Family history of HF (n, \%) & $80(29.2)$ \\
\hline Past chemotherapy (n, \%) & $25(9.1)$ \\
\hline Past heart disease $(n, \%)$ & $16(5.8)$ \\
\hline \multicolumn{2}{|l|}{ Medication } \\
\hline Insulin (n, \%) & $65(23.7)$ \\
\hline Metformin $(n, \%)$ & $184(67.2)$ \\
\hline $\operatorname{ACEi} / \operatorname{ARB}(n, \%)$ & $183(66.8)$ \\
\hline Beta-blockers (n, \%) & $15(5.5)$ \\
\hline Calcium antagonists $(\mathrm{n}, \%)$ & $64(23.4)$ \\
\hline Diuretics $(n, \%)$ & $31(11.3)$ \\
\hline Lipid lowering meds (n, \%) & $133(48.5)$ \\
\hline \multicolumn{2}{|l|}{ Questionnaire } \\
\hline PHQ-9 score & $3.2 \pm 4.3$ \\
\hline $0-4$ & $210(76.7)$ \\
\hline $5-9$ & $37(13.5)$ \\
\hline $10-20$ & $25(9.1)$ \\
\hline$\geq 20$ & $2(0.7)$ \\
\hline \multicolumn{2}{|l|}{ Echocardiography } \\
\hline LV ejection fraction (\%) & $63.1 \pm 6.4$ \\
\hline Mitral early-diastolic inflow velocity (E wave) $(\mathrm{m} / \mathrm{s})$ & $0.65 \pm 0.17$ \\
\hline Mitral late-diastolic inflow velocity (A wave) (m/s) & $0.83 \pm 0.19$ \\
\hline Transmitral diastolic flow velocity ratio (E/A) & $0.79 \pm 0.22$ \\
\hline Early diastolic mitral annular velocity $\left(\mathrm{e}^{\prime}\right)(\mathrm{m} / \mathrm{s})$ & $0.08 \pm 0.02$ \\
\hline Mitral E/e' septal-lateral ratio (E/e') & $9.2 \pm 2.8$ \\
\hline E/e' ratio $>13(n, \%)$ & $29(10.6)$ \\
\hline Deceleration time (DT) (s) & $246.8 \pm 52.4$ \\
\hline LV mass index $\left(\mathrm{g} / \mathrm{m}^{2}\right)$ & $85.7 \pm 19.0$ \\
\hline LV mass index $\left(\mathrm{g} / \mathrm{m}^{1.7}\right)$ & $74.4 \pm 20.8$ \\
\hline LV hypertrophy $(n, \%)^{a}$ & $36(13.2)$ \\
\hline \multicolumn{2}{|l|}{ Biochemical characteristics } \\
\hline $\mathrm{HbA} 1 \mathrm{c}(\mathrm{mmol} / \mathrm{mol})(\mathrm{n}=274)$ & $53.5 \pm 10.1$ \\
\hline Fasting glucose $(\mu \mathrm{mol} / L)(n=109)$ & $8.3 \pm 3.5$ \\
\hline Creatinine $(\mu \mathrm{mol} / L)(n=186)$ & $81.3 \pm 24.0$ \\
\hline \multicolumn{2}{|l|}{$\operatorname{eGFR}\left(\mathrm{mL} / \mathrm{min} / 1.73 \mathrm{~m}^{2}\right)(\mathrm{n}=187)$} \\
\hline$\geq 90$ & $37(19.8)$ \\
\hline $60-89$ & $115(61.5)$ \\
\hline $45-59$ & $25(13.4)$ \\
\hline
\end{tabular}


Table 1 continued

\begin{tabular}{ll}
\hline $30-44$ & $9(4.8)$ \\
$15-29$ & $1(0.5)$ \\
\hline
\end{tabular}

a LV hypertrophy was defined as LVMi $>115 \mathrm{~g} / \mathrm{m}^{2}$ for males, $>95 \mathrm{~g} / \mathrm{m}^{2}$ for female

depression; these patients had higher BMI and more central obesity, more insulin use and higher HbA1c level. However, there was no difference in age, gender, blood pressure, heart rate and other risk factors of HF and echocardiographic parameters among patients with and without depression. The only independent determinant of PHQ-9 score detected by linear regression was BMI.

\section{Follow-up}

After a median follow-up time of 1.5 years (range $0.5-3$ years), 2 of 274 T2DM participants $(0.7 \%)$ were lost to follow-up and 18 of 274 participants $(6.6 \%)$ were alive but unable to attend for clinic review (Fig. 1). This group was no different from the remaining 254 individuals who

Table 2 Baseline demographic, clinical and echocardiographic variable comparisons among T2DM patients categorized by the presence of depression $(n=254)$

\begin{tabular}{|c|c|c|c|}
\hline & $\begin{array}{l}\text { Depression } \\
(n=25)\end{array}$ & $\begin{array}{l}\text { No depression } \\
(\mathrm{n}=229)\end{array}$ & $\mathbf{p}$ \\
\hline \multicolumn{4}{|l|}{ Demographic and clinical characteristics } \\
\hline Age (years) & $70.6 \pm 3.8$ & $70.9 \pm 4.4$ & 0.418 \\
\hline Male gender $(n, \%)$ & $11(44.0)$ & $131(57.2)$ & 0.208 \\
\hline Weight (kg) & $92.6 \pm 22.8$ & $85.1 \pm 16.5$ & 0.122 \\
\hline $\mathrm{BMI}\left(\mathrm{kg} / \mathrm{m}^{2}\right)$ & $34.1 \pm 7.8$ & $29.8 \pm 5.6$ & 0.012 \\
\hline Waist circumference (cm) & $109.0 \pm 14.2$ & $102.4 \pm 13.1$ & 0.032 \\
\hline Obesity $(n, \%)$ & $18(72.0)$ & $106(46.3)$ & 0.015 \\
\hline Heart rate (n/min) & $70 \pm 11$ & $68 \pm 11$ & 0.280 \\
\hline Systolic blood pressure (mmHg) & $138 \pm 17$ & $139 \pm 14$ & 0.936 \\
\hline Diastolic blood pressure $(\mathrm{mmHg})$ & $80 \pm 12$ & $81 \pm 9$ & 0.748 \\
\hline Hypertension (n, \%) & $19(76.0)$ & $171(74.7)$ & 0.985 \\
\hline Family history of HF (n, \%) & $10(40.0)$ & $63(27.5)$ & 0.191 \\
\hline Past chemotherapy (n, \%) & $4(16.0)$ & $18(7.9)$ & 0.170 \\
\hline Past heart disease $(n, \%)$ & $3(12.0)$ & $11(4.8)$ & 0.135 \\
\hline $\mathrm{HbA} 1 \mathrm{c}(\mathrm{mmol} / \mathrm{mol})$ & $57.6 \pm 10.6$ & $53.0 \pm 10.0$ & 0.049 \\
\hline $\mathrm{HbA} 1 \mathrm{c}>64 \mathrm{mmol} / \mathrm{mol}(\mathrm{n}, \%)$ & $8(32)$ & $24(10.5)$ & 0.002 \\
\hline \multicolumn{4}{|l|}{ Medication } \\
\hline Insulin $(n, \%)$ & $11(44.0)$ & $49(21.4)$ & 0.012 \\
\hline Metformin $(n, \%)$ & $18(72.0)$ & $157(68.6)$ & 0.725 \\
\hline $\operatorname{ACEi} / \operatorname{ARB}(n, \%)$ & $19(76.0)$ & $152(66.4)$ & 0.331 \\
\hline Beta-blockers $(n, \%)$ & $1(4.0)$ & $14(6.1)$ & 0.571 \\
\hline Calcium antagonists $(\mathrm{n}, \%)$ & $7(28.0)$ & $54(23.6)$ & 0.524 \\
\hline Diuretics $(n, \%)$ & $4(16.0)$ & $23(10.0)$ & 0.360 \\
\hline Lipid lowering meds ( $n, \%)$ & $14(56.0)$ & $109(47.5)$ & 0.426 \\
\hline \multicolumn{4}{|l|}{ Echocardiography } \\
\hline LV ejection fraction (\%) & $61.5 \pm 8.7$ & $63.2 \pm 6.2$ & 0.222 \\
\hline Mitral early-diastolic inflow velocity (E wave) $(\mathrm{m} / \mathrm{s})$ & $0.62 \pm 0.18$ & $0.65 \pm 0.16$ & 0.530 \\
\hline Mitral late-diastolic inflow velocity (A wave) (m/s) & $0.81 \pm 0.16$ & $0.83 \pm 0.19$ & 0.525 \\
\hline Transmitral diastolic flow velocity ratio (E/A) & $0.79 \pm 0.21$ & $0.77 \pm 0.25$ & 0.693 \\
\hline Early diastolic mitral annular velocity $\left(\mathrm{e}^{\prime}\right)(\mathrm{m} / \mathrm{s})$ & $0.07 \pm 0.01$ & $0.08 \pm 0.02$ & 0.852 \\
\hline Mitral E/e' septal-lateral ratio (E/e') & $8.6 \pm 1.9$ & $9.2 \pm 2.8$ & 0.336 \\
\hline E/e' ratio $>13(n, \%)$ & $1(4.0)$ & $25(10.9)$ & 0.280 \\
\hline Deceleration time (DT) (s) & $231.6 \pm 50.4$ & $248.6 \pm 52.9$ & 0.129 \\
\hline LV mass index $\left(\mathrm{g} / \mathrm{m}^{2}\right)$ & $87.3 \pm 16.1$ & $85.4 \pm 19.6$ & 0.602 \\
\hline LV mass index $\left(\mathrm{g} / \mathrm{m}^{1.7}\right)$ & $82.3 \pm 27.0$ & $73.6 \pm 20.2$ & 0.130 \\
\hline LV hypertrophy $(n, \%)^{a}$ & $2(8.0)$ & $33(14.4)$ & 0.998 \\
\hline
\end{tabular}

Italic values indicate significant associations

${ }^{a}$ LV hypertrophy was defined as LVMi $>115 \mathrm{~g} / \mathrm{m}^{2}$ for males, $>95 \mathrm{~g} / \mathrm{m}^{2}$ for females 


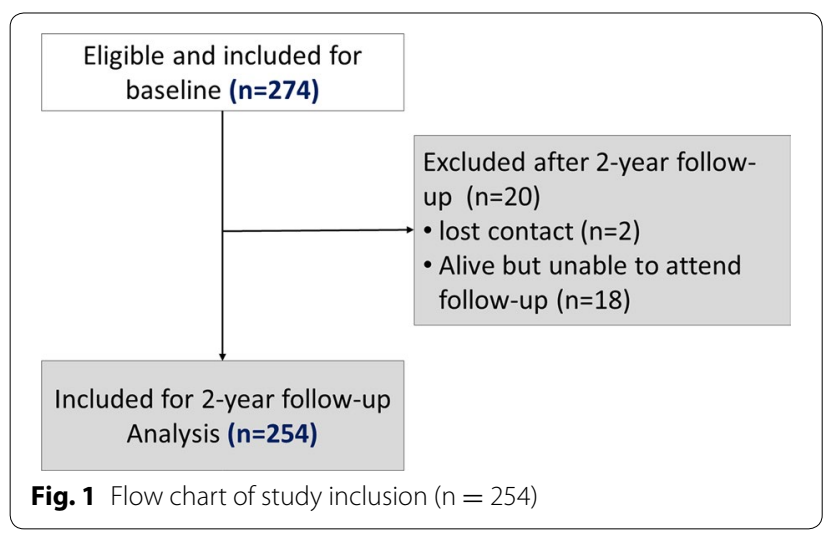

completed follow-up (Appendix 1: Table 5). The primary composite endpoint was reached by 40 patients; 37 patients developed new-onset HF and 3 died, giving an event rate of 107/1000 person-years.

Cox regression analysis was performed to analyze the association between clinical and biochemical variables and echocardiographic parameters of interest and the time to the primary composite endpoint (Table 3). Patients with events were characterized by obesity, worse glycemic control, baseline LVEF, LV mass (but not diastolic function parameters), beta blockade and depression. PHQ-9 scores were significantly associated with events, both as a continuous or binomial covariate. When PHQ-9 score was categorized into three levels (0-4, 5-9 and $\geq 10$ ), PHQ-9 $\geq 10$ was independently associated with events. The cumulative survival of the included 254 elderly asymptomatic T2DM stratified by the severity of depression is shown in Appendix 3: Fig. 4. The cumulative survival for patients with PHQ- 9 score $\geq 10$ was the lowest. A multivariable Cox regression model (informed by significant univariable clinical associations and echocardiographic parameters of interest) was constructed to determine the independent predictors of the composite endpoint (Table 4). Obesity, LVH and depression were associated with increased risks of the composite endpoint.

\section{Prediction of HF in T2DM}

A competing risk analysis that controlled for age, obesity and poor glycemic control was performed to assess whether depression and echocardiographic parameters of interest were associated with incident HF in elderly asymptomatic patients with T2DM (Fig. 2). The baseline clinical model, showing an independent effect of obesity $(\mathrm{p}<0.001)$, and poor glycemic control $(\mathrm{p}=0.02)$ on incident events, was improved by addition of echocardiographic features $(\mathrm{LVH}, \mathrm{p}=0.001)$. However, the addition
Table 3 Univariable Cox regression analysis for primary composite endpoint in $\mathbf{2 5 4}$ elderly asymptomatic patients with T2DM

\begin{tabular}{|c|c|c|}
\hline & $\mathrm{HR}(95 \% \mathrm{Cl})$ & $p$ value \\
\hline \multicolumn{3}{|l|}{ Demographic and clinical characteristics } \\
\hline Age & $1.06(0.99,1.32)$ & 0.064 \\
\hline Male gender (yes/no) & $1.81(0.92,3.56)$ & 0.086 \\
\hline Weight & $1.04(1.02,1.05)$ & $<0.001$ \\
\hline BMl & $1.10(1.06,1.15)$ & $<0.001$ \\
\hline Waist circumference & $1.05(1.03,1.08)$ & $<0.001$ \\
\hline Obesity (yes/no) & $3.61(1.76,7.39)$ & $<0.001$ \\
\hline Heart rate & $0.99(0.97,1.03)$ & 0.727 \\
\hline Systolic blood pressure & $0.99(0.97,1.01)$ & 0.314 \\
\hline Diastolic blood pressure & $0.90(0.99,1.03)$ & 0.895 \\
\hline Hypertension (yes/no) & $1.07(0.52,2.19)$ & 0.854 \\
\hline Family history of HF (yes/no) & $0.70(0.33,1.47)$ & 0.349 \\
\hline Past chemotherapy (yes/no) & $1.54(0.60,3.93)$ & 0.536 \\
\hline Past heart disease (yes/no) & $1.46(0.45,4.74)$ & 0.529 \\
\hline $\mathrm{HbA1c}(\mathrm{mmol} / \mathrm{mol})$ & $1.03(1.01,1.06)$ & 0.009 \\
\hline $\mathrm{HbA} 1 \mathrm{c}>64 \mathrm{mmol} / \mathrm{mol}(\mathrm{n}, \%)$ & $3.27(1.66,6.43)$ & 0.001 \\
\hline \multicolumn{3}{|l|}{ Medication } \\
\hline Insulin (yes/no) & $1.77(0.92,3.39)$ & 0.086 \\
\hline Metformin (yes/no) & $0.72(0.38,1.36)$ & 0.310 \\
\hline ACEi/ARB (yes/no) & $1.12(0.57,2.20)$ & 0.749 \\
\hline Beta-blockers (yes/no) & $3.25(1.36,7.77)$ & 0.008 \\
\hline Calcium antagonists (yes/no) & $0.50(0.21,1.18)$ & 0.114 \\
\hline Diuretics (yes/no) & $0.91(0.33,2.65)$ & 0.909 \\
\hline Lipid lowering med (yes/no) & $1.32(0.71,2.48)$ & 0.382 \\
\hline \multicolumn{3}{|l|}{ Questionnaire } \\
\hline PHQ-9 score (continuous) & $1.08(1.01,1.16)$ & 0.021 \\
\hline PHQ-9 score $\geq 10$ (yes/no) & $3.21(1.41,7.30)$ & 0.005 \\
\hline \multicolumn{3}{|l|}{ PHQ-9 score (categorical) } \\
\hline $0-4$ & Ref & \\
\hline $5-9$ & $0.58(0.18,1.89)$ & 0.362 \\
\hline$\geq 10$ & $3.01(1.32,6.89)$ & 0.009 \\
\hline \multicolumn{3}{|l|}{ Echocardiography } \\
\hline LV ejection fraction & $0.95(0.90,0.99)$ & 0.018 \\
\hline $\begin{array}{l}\text { Mitral early-diastolic inflow velocity ( } E \\
\text { wave) }\end{array}$ & $3.46(0.54,22.39)$ & 0.192 \\
\hline Mitral late-diastolic inflow velocity (A wave) & $1.81(0.32,10.31)$ & 0.503 \\
\hline Transmitral diastolic flow velocity ratio (E/A) & $0.92(0.16,5.31)$ & 0.929 \\
\hline Early diastolic mitral annular velocity $\left(e^{\prime}\right)$ & $1.05(0.86,1.28)$ & 0.644 \\
\hline Mitral E/e' septal-lateral ratio & $1.05(0.94,1.17)$ & 0.437 \\
\hline E/e' ratio $>13$ (yes/no) & $1.04(0.37,2.94)$ & 0.934 \\
\hline Deceleration time (DT) & $0.99(0.99,1.00)$ & 0.363 \\
\hline LV mass index $\left(\mathrm{g} / \mathrm{m}^{2}\right)$ & $1.03(1.02,1.04)$ & $<0.001$ \\
\hline LV mass index $\left(\mathrm{g} / \mathrm{m}^{1.7}\right)$ & $1.03(1.02,1.04)$ & $<0.001$ \\
\hline LV hypertrophy (yes/no) a & $3.92(2.04,7.52)$ & $<0.001$ \\
\hline
\end{tabular}

Italic values indicate significant associations

a LV hypertrophy was defined as LVMi $>115 \mathrm{~g} / \mathrm{m}^{2}$ for males, $>95 \mathrm{~g} / \mathrm{m}^{2}$ for females 
Table 4 Cox regression analysis for primary composite endpoint in 254 elderly asymptomatic patients with T2DM

\begin{tabular}{|c|c|c|c|c|c|c|c|}
\hline Variable & No. of patients & No. of HF & No. of death & $\begin{array}{l}\text { Unadjusted HR (95\% } \\
\text { Cl) } \\
\text { p value }\end{array}$ & $\begin{array}{l}\text { LVH-adjusted } \\
\text { HR }(95 \% \mathrm{CI})^{\mathrm{a}} \\
\text { p value }\end{array}$ & $\begin{array}{l}\text { E/e'-adjusted } \\
\text { HR }(95 \% \mathrm{Cl})^{\mathbf{b}} \\
\text { p value }\end{array}$ & $\begin{array}{l}\text { Adjusted HR } \\
(95 \% \mathrm{Cl})^{c} \\
\text { p value }\end{array}$ \\
\hline Age & 254 & 37 & 3 & $\begin{array}{l}1.06(0.99,1.13) \\
0.064\end{array}$ & - & - & $\begin{array}{l}1.06(0.99,1.14) \\
0.055\end{array}$ \\
\hline Male gender & 142 & 25 & 3 & $\begin{array}{l}1.81(0.92,3.56) \\
0.086\end{array}$ & - & - & $\begin{array}{l}1.36(0.61,2.92) \\
0.466\end{array}$ \\
\hline Obesity & 124 & 29 & 1 & $\begin{array}{l}3.61(1.76,7.39) \\
<0.001\end{array}$ & $\begin{array}{l}2.87(1.38,5.98) \\
0.005\end{array}$ & $\begin{array}{l}3.27(1.58,5.75) \\
0.001\end{array}$ & $\begin{array}{l}2.97(1.44,6.30) \\
0.004\end{array}$ \\
\hline $\mathrm{HbA1c}$ & 32 & 10 & 2 & $\begin{array}{l}3.27(1.66,6.43) \\
0.001\end{array}$ & $\begin{array}{l}2.04(0.99,4.22) \\
0.054\end{array}$ & $\begin{array}{l}2.47(1.22,5.00) \\
0.012\end{array}$ & $\begin{array}{l}2.01(0.93,4.10) \\
0.077\end{array}$ \\
\hline LVH & 35 & 13 & 1 & $\begin{array}{l}3.92(2.04,7.52) \\
<0.001\end{array}$ & $\begin{array}{l}3.24(1.65,6.38) \\
0.001\end{array}$ & - & $\begin{array}{l}2.67(1.25,5.99) \\
0.011\end{array}$ \\
\hline$E / e^{\prime}$ & 26 & 4 & 0 & $\begin{array}{l}1.04(0.37,2.94) \\
0.934\end{array}$ & - & $\begin{array}{l}1.11(0.39,3.18) \\
0.845\end{array}$ & $\begin{array}{l}0.82(0.26,2.52) \\
0.724\end{array}$ \\
\hline Depression & 25 & 7 & 0 & $\begin{array}{l}3.21(1.41,7.30) \\
0.005\end{array}$ & $\begin{array}{l}2.80(1.16,6.76) \\
0.022\end{array}$ & $\begin{array}{l}2.39(1.01,5.67) \\
0.048\end{array}$ & $\begin{array}{l}3.14(1.27,7.74) \\
0.013\end{array}$ \\
\hline
\end{tabular}

Obesity, BMI $\geq 30 \mathrm{~kg} / \mathrm{m}^{2}$; poor HbA1c, ICFFstd-HbA1c $>64 \mathrm{mmol} / \mathrm{mol}$; LVH, left ventricular hypertrophy, cutoff $>115 \mathrm{~g} / \mathrm{m}^{2}$ for males, $>95 \mathrm{~g} / \mathrm{m}^{2}$ for females; E/e' ratio, cutoff $>13$; depression, the score of PHQ-9 questionnaire $\geq 10$

$H R$ hazard ratio, $\mathrm{Cl}$ confidence interval

Italic values indicate significant associations

a In the multivariate cox model, obesity, poor HbA1c, LVH and depression were entered into the model

b In the multivariate cox model, obesity, poor $\mathrm{HbA} 1 \mathrm{c}, \mathrm{E} / \mathrm{e}^{\prime}$ and depression were entered into the model

c In the multivariate cox model, age, male gender, obesity, poor $\mathrm{HbA} 1 \mathrm{c}, \mathrm{LVH}, \mathrm{E} / \mathrm{e}^{\prime}$ and depression were entered into the model

of depression $(\mathrm{p}=0.017)$ had incremental predictive power to clinical, biochemical and echocardiographic variables for the prediction of incident HF (Fig. 2).

The cumulative incidence of HF with time among elderly asymptomatic T2DM stratified by depression status is shown in Fig. 3. By the end of the follow-up, considering the competing risk, the cumulative incidence of HF was 0.36 in patients with depression and was 0.15 in patients without depression. Gray's test also showed that the cumulative incidence of HF was significantly lower in patients with depression than those patients without depression $(\mathrm{p}<0.001)$.

\section{Discussion}

The results of this study show that depression (defined as PHQ-9 score $\geq 10$ ) was significantly associated with increased risk of incident HF during follow-up of asymptomatic elderly patients with T2DM and preserved EF. This association was independent of clinical factors (including age, gender and BMI) and echocardiographic features such as LV hypertrophy and diastolic function. The presence of depression increased the likelihood of incident HF by 2.5 -fold, and increased the composite endpoint 3.1-fold, compared with those without depression. Although depression has been linked with adverse outcomes in HF patients, to our knowledge, this is the first study to show an independent association between depression and incident HF in DM.

\section{Depression and HF}

Depression is a common co-morbidity of HF, with variable reports of its prevalence. A meta-analysis of 25 studies showed depression to be present in 11\% HF in NYHA (New York Heart Association) functional class I, 20\% with class II, and approximately $40 \%$ of class III and IV HF. Depression is more widely diagnosed when this diagnosis is made by questionnaire (34\%), and less with clinical interview (19\%) [14].

Depression is an independent predictor of adverse clinical outcomes in HF, and increases the risk of mortality by $40-50 \%$ [15] In elderly patients with newly diagnosed HF, the presence of depression increased the risk of hospital admission by $20 \%$, and depression screening has been suggested as a routine assessment at the time of HF diagnosis [16]. Even mild depression (defined as PHQ-9 score $\geq 5$ ) has been associated with mortality and re-hospitalization in HF [17]. Depression is also associated with a 2.4-fold increment of mortality, independent of age, gender, etiology, NYHA class, EF and LV systolic dysfunction [18].

Few previous studies have sought whether psychosocial factors could independently predict incident HF 


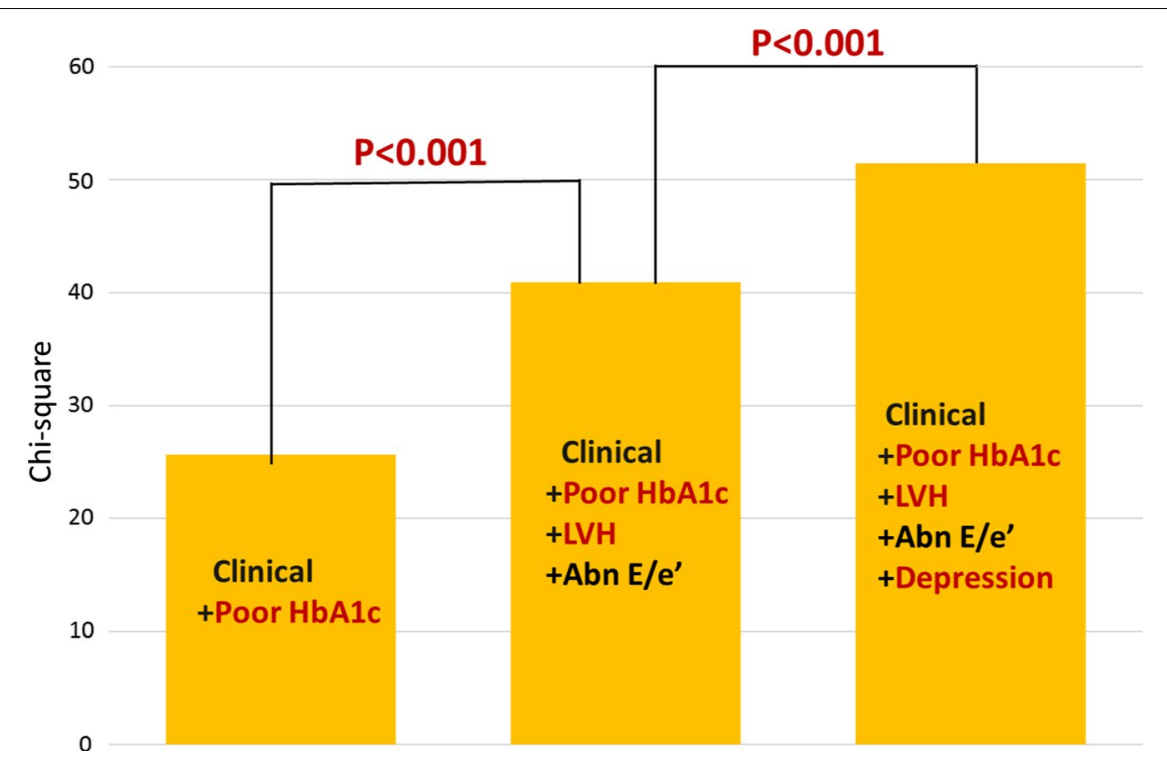

\begin{tabular}{|c|c|c|c|}
\hline & Model 1 & Model 2 & Model 3 \\
\hline \multirow[t]{2}{*}{$\begin{array}{l}\text { Chi-square } \\
\text { P for chi-square } \\
\text { change }\end{array}$} & 25.63 & $\begin{array}{l}40.92 \\
\mathrm{P}<0.001\end{array}$ & $\begin{array}{l}51.44 \\
\mathrm{P}<0.001\end{array}$ \\
\hline & $\begin{array}{l}\text { HR }(95 \% \text { CI }) \\
\text { P value }\end{array}$ & $\begin{array}{l}\text { HR }(95 \% \text { CI }) \\
\text { P value }\end{array}$ & $\begin{array}{l}\text { HR }(95 \% \mathrm{CI}) \\
\text { P value }\end{array}$ \\
\hline Age & $\begin{array}{l}1.05(0.98,1.12) \\
0.131\end{array}$ & $\begin{array}{l}1.02(0.99,1.11) \\
0.124\end{array}$ & $\begin{array}{l}1.07(1.01,1.14) \\
\mathbf{0 . 0 3 4}\end{array}$ \\
\hline Male gender & $\begin{array}{l}1.54(0.78,3.06) \\
0.212\end{array}$ & $\begin{array}{l}1.10(0.52,2.32) \\
0.798\end{array}$ & $\begin{array}{l}1.14(0.53,2.44) \\
0.738\end{array}$ \\
\hline Obesity & $\begin{array}{l}4.49(2.12,9.52) \\
<\mathbf{0 . 0 0 1}\end{array}$ & $\begin{array}{l}3.85(1.83,8.12) \\
<\mathbf{0 . 0 0 1}\end{array}$ & $\begin{array}{l}3.55(1.64,7.66) \\
\mathbf{0 . 0 0 1}\end{array}$ \\
\hline Poor HbA1c & $\begin{array}{l}2.06(1.11,3.83) \\
\mathbf{0 . 0 2 2}\end{array}$ & $\begin{array}{l}2.41(1.27,4.58) \\
\mathbf{0 . 0 0 7}\end{array}$ & $\begin{array}{l}2.29(1.18,4.45) \\
\mathbf{0 . 0 1 4}\end{array}$ \\
\hline LVH & & $\begin{array}{l}3.51(1.67,7.37) \\
\mathbf{0 . 0 0 1}\end{array}$ & $\begin{array}{l}3.48(1.60,7.58) \\
0.002\end{array}$ \\
\hline Abnormal E/e' & & $\begin{array}{l}0.90(0.31,2.63) \\
0.850\end{array}$ & $\begin{array}{l}0.99(0.32,3.02) \\
0.980\end{array}$ \\
\hline Depression & & & $\begin{array}{l}2.54(1.18,5.46) \\
\mathbf{0 . 0 1 7}\end{array}$ \\
\hline
\end{tabular}

Fig. 2 Prediction of incident HF in elderly asymptomatic patients with T2DM (competing risk analysis). LVH and depression showed incremental value over clinical parameters for incident HF

$[5,19,20]$. Abramson et al. [5] first found that depression, as defined by Center for Epidemiological Studies Depression Scale (CES-D) $\geq 16$, was independently associated with a substantial increase in the risk of HF among elderly patients with isolated systolic hypertension. Williams et al. [20] found an independent association between depression (CES-D $\geq 20$, and incident $\mathrm{HF}$ among elderly women but not elderly men. The results from prospective cohort studies are contradictory-the Nord-Trøndelag Health (HUNT) Study demonstrated the prospective association of self-reported depression at baseline with future HF in a dose-response manner, independent of a large number of baseline cardiovascular risk factors, acute myocardial infarction (AMI) and several chronic disorders [19]. However, the Multi-Ethnic Study of Atherosclerosis (MESA) found no significant 


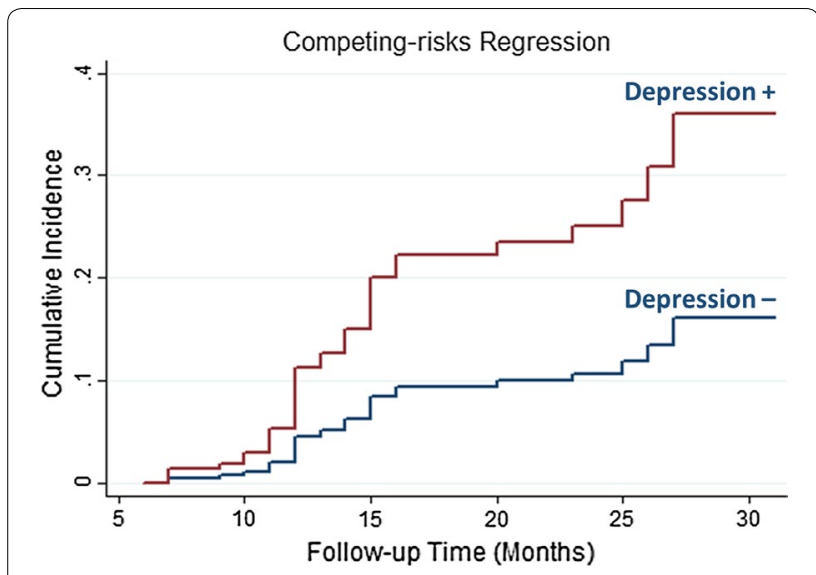

Fig. 3 Cumulative incidence estimates of HF in elderly asymptomatic T2DM stratified by patients with and without depression

association between depression (CES-D scale $\geq 16$ ), and subsequent HF in an older population. However, in participants reporting fair/poor health status at baseline, this association was significant [21]. It is certainly plausible that sympathetic overactivity might be associated with both HF mortality and HF incidence, but this remains unproven.

\section{Depression and diabetes}

About $20-30 \%$ of elderly patients with diabetes suffer from clinical depression, and around $10 \%$ of them have major depression [22]. Even though the relationship between depression and diabetes is incompletely understood, it is clear that depression has an adverse impact on the course of diabetes, and diabetes complications may result in both the risk of depression and worsening the course of depression. Their association is primarily driven by somatic-affective symptoms of depression [23]. Additionally, the duration of depression lasts longer (usually $\geq 2$ years) in most diabetic patients and the relapse rate is relatively high [24]. A previous study with 10-year follow-up also showed that all-cause of mortality increased with the severity of depression in diabetic subjects [25].

\section{$\mathrm{HF}$ in diabetes}

Numerous epidemiological studies have indicated the strong association between diabetes and the development of HF $[2,26]$. The underlying mechanisms are multiple, but there is a growing recognition of a primary myocardial disease process-"diabetic cardiomyopathy"- that may lead to LV dysfunction, and subsequently HF. Hyperinsulinemia, inflammation and oxidative stress result in increased fatty acid metabolism and fetal gene expression [27]. The resulting pathophysiological changes include impaired myocardial relaxation and cardiomyocyte resting tension, activation of the renin-angiotensin system (leading to vasoconstriction, salt and water retention, and fibrosis) and diabetic autonomic neuropathy. These changes lead to impaired diastolic and systolic function [28]. Furthermore, overweight has been proved to have a greater effect on LV function in diabetes than in non-diabetes [29]. In our study, obesity has emerged as an important association of incident HF.

Several shared pathophysiological mechanisms may link T2DM, depressive symptoms and incident HF. Proinflammatory cytokines and platelet activation, rhythm disturbances, neurohormonal activation, endothelial dysfunction and hypercoagulability are present in patients with depression [30]. These pathophysiological changes adversely influence the cardiovascular system and have been postulated to play an important role in the development and progression of HF [30]. Endothelial dysfunction plays an important role in cardiovascular homeostasis by producing various vascular regulators that mediate fibrinolysis, hypercoagulability, platelet activation and vascular tone, disturbances of which constitute the step linking diabetes to cardiovascular events [31]. Hyperglycemia and insulin resistance are associated with endothelial dysfunction [32] and cardiac damage [31]. Impaired nitric oxide production and oxidative stress may also lead to endothelial dysfunction, impaired vasodilation and large vessel impairment [31]. Hyperglycemia and hyperinsulinemia have also been significant contributors to cardiovascular complications through their role in stimulating coagulation and impairing fibrinolysis [33]. Pro-inflammatory cytokines are common in diabetes and significantly increase the risk of progression of cardiovascular complications at all stages [34]. Additionally, patients with depression are more likely to take up risky lifestyles and behaviors and more likely to show non-adherence to medical regimens and behavior recommendations that affects the prognosis of HF [35]. Depression may be also involved with the lower social support that is implicated in the development of HF.

\section{Limitation}

In the present study, the population were selected from the community with preserved EF, so diabetes patients with established asymptomatic LV systolic dysfunction were excluded. We did not have data on brain natriuretic peptide (BNP). Although this biomarker has an established role in the acute care setting to assist the diagnosis of congestive heart failure and in predicting long-term outcomes, its utility for the early detection of HF with preserved ejection fraction (HFpEF) is more controversial. Its response to raised filling pressure is blunted 
in overweight patients compared with normal weight patients, regardless of the presence or absence of cardiovascular disease [36].

We used self-reported measures of symptoms of depression rather than diagnostic interviews. However, the use of the PHQ-9 survey for screening depression has been validated and has been recommended by the American Heart Association for the diagnosis of depression in coronary heart disease [37]. We acknowledge that the lower sensitivity of PHQ-9 relative to other markers [38] means that it may not capture all patients. However, its high specificity can identify patients at high risk for adverse cardiovascular events. While the study shows a connection of depression with LV dysfunction, it does not explain the reasons for depression. In our study, the factor associated with depression was advanced BMI. Previous research has demonstrated the association of diabetes-related complications, longer duration of diabetes, more demanding regimens, inactivity, current smoking and overweight as potential risk factors for depression in T2DM [39].

While we excluded patients with reported history of CAD including CABG and/or AMI with regional scar, testing for occult CAD was not possible in this community-based study. It is therefore possible that some of the abnormal cardiac function signal is attributable to coronary artery disease. In addition, the blood examination in the cohort such as BNP or NT-pro BNP were not part of this study. Lastly, despite the longitudinal study design and high-risk nature of this population, the number of events was relatively small.

\section{Conclusion}

In this community cohort of asymptomatic patients with T2DM, depression was prevalent, and significantly associated with incident HF over 2-years of observation. This association is not explained by baseline demographic characteristics, glycemic control and LV dysfunction [including LV hypotrophy and subclinical diastolic dysfunction (evidenced by $\left.E / e^{\prime}\right)$ ]. The mechanism of this association requires further investigation, and although it remains unclear as to whether a depression intervention in T2DM may prevent HF, depressed patients may warrant closer monitoring for the development of HF.

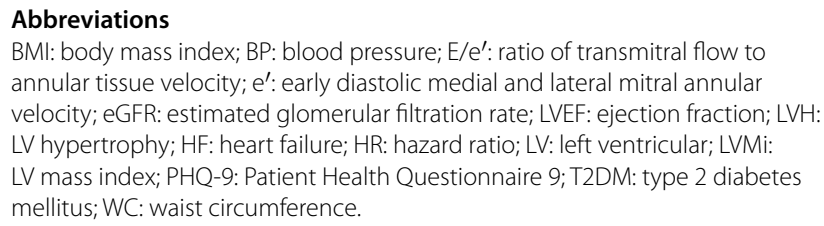
annular tissue velocity; $\mathrm{e}^{\prime}$ : early diastolic medial and lateral mitral annular velocity; eGFR: estimated glomerular filtration rate; LVEF: ejection fraction; LVH: LV hypertrophy; HF: heart failure; HR: hazard ratio; LV: left ventricular; LVMi: LV mass index; PHQ-9: Patient Health Questionnaire 9; T2DM: type 2 diabetes mellitus; WC: waist circumference.

\section{Authors' contributions}

YW co-designed the study, recruited patients, collected and analyzed data, write the initial draft. HY, MN, JB, KN-recruited patients, collected and analyzed different components of data, revised paper for content. THMdesigned the study, obtained resources, analyzed data, revised the initial draft. All authors read and approved the final manuscript.

\section{Author details}

${ }^{1}$ Menzies Institute for Medical Research, Baker Heart and Diabetes Institute, Melbourne, Australia. ${ }^{2}$ Faculty of Health Sciences, Baker Heart and Diabetes Institute, Melbourne, Australia. ${ }^{3}$ Baker Heart and Diabetes Institute, 75 Commercial Road, Melbourne, VIC 3004, Australia.

\section{Acknowledgements}

The authors gratefully acknowledge the contribution of our tireless volunteer coordinators, Diane Binns, Jasmine Prichard, and Jane Mitchell.

Competing interests

The authors declare that they have no competing interests.

Availability of data and materials

Primary material is held by the authors.

Consent for publication

Not applicable.

\section{Ethics approval and consent to participate}

The study was approved by the Tasmanian Human Research Ethics Committee, and written informed consent was obtained from all patients.

Funding

This study was partially supported by Tasmanian Community Fund and Diabetes Australia Research Trust. Neither of these agencies had any role in design, analysis, or interpretation of this study.

\section{Appendices \\ Appendix 1 \\ See Table 5.}


Table 5 Comparison of baseline characteristics between patients who completed follow-up study $(n=254)$ and patients who loss to follow-up study $(n=20)$

\begin{tabular}{|c|c|c|c|}
\hline & $\begin{array}{l}\text { Completed } \\
n=254\end{array}$ & $\begin{array}{l}\text { Loss to FU } \\
n=20\end{array}$ & $\mathrm{p}$ value \\
\hline \multicolumn{4}{|c|}{ Demographic and clinical characteristics } \\
\hline Age (years) & $70.9 \pm 4.3$ & $72 \pm 5.1$ & 0.341 \\
\hline Male gender $(n, \%)$ & $142(55.9)$ & $8(40.0)$ & 0.389 \\
\hline Weight (kg) & $85.8 \pm 17.3$ & $85.7 \pm 16.7$ & 0.820 \\
\hline BMI $\left(\mathrm{kg} / \mathrm{m}^{2}\right)$ & $30.2 \pm 5.9$ & $31.1 \pm 5.6$ & 0.536 \\
\hline Waist circumference (cm) & $103.1 \pm 13.3$ & $107.3 \pm 15.3$ & 0.255 \\
\hline Obesity $(n, \%)$ & $124(48.8)$ & $11(55.0)$ & 0.811 \\
\hline Heart rate (n/min) & $69 \pm 11$ & $71 \pm 13$ & 0.445 \\
\hline Systolic blood pressure $(\mathrm{mmHg})$ & $139 \pm 14$ & $141 \pm 23$ & 0.550 \\
\hline $\begin{array}{l}\text { Diastolic blood pressure } \\
(\mathrm{mmHg})\end{array}$ & $81 \pm 10$ & $80 \pm 10$ & 0.613 \\
\hline Hypertension (n, \%) & $190(74.8)$ & $14(70.0)$ & 0.195 \\
\hline Family history of HF (n, \%) & $73(28.7)$ & $7(35.0)$ & 0.518 \\
\hline Past chemotherapy (n, \%) & $22(8.7)$ & $3(15.0)$ & 0.403 \\
\hline Past heart disease $(\mathrm{n}, \%)$ & $14(5.5)$ & $2(10.0)$ & 0.103 \\
\hline $\mathrm{HbA} 1 \mathrm{c}(\mathrm{mmol} / \mathrm{mol})$ & $53.4 \pm 10.2$ & $54.2 \pm 9.5$ & 0.733 \\
\hline $\mathrm{HbA} 1 \mathrm{c}>64 \mathrm{mmol} / \mathrm{mol}(\mathrm{n}, \%)$ & $32(12.6)$ & $4(20)$ & 0.245 \\
\hline \multicolumn{4}{|l|}{ Medication } \\
\hline Insulin (n, \%) & $60(23.6)$ & $5(25.0)$ & 0.037 \\
\hline Metformin (n, \%) & $175(68.9)$ & $9(45.0)$ & 0.244 \\
\hline $\operatorname{ACEi} / \operatorname{ARB}(n, \%)$ & $171(67.3)$ & $12(60.0)$ & 0.630 \\
\hline Beta-blockers (n, \%) & $15(5.9)$ & $0(0)$ & $<0.001$ \\
\hline Calcium antagonists (n, \%) & $62(24.3)$ & $2(10.0)$ & 0.093 \\
\hline Diuretics $(n, \%)$ & $27(10.6)$ & $4(20.0)$ & 0.445 \\
\hline Lipid lowering meds (n, \%) & $123(48.4)$ & $10(50.0)$ & 0.560 \\
\hline \multicolumn{4}{|l|}{ Questionnaire } \\
\hline PHQ-9 score & $3.2 \pm 4.3$ & $2.8 \pm 5.1$ & 0.787 \\
\hline $0-4$ & $194(76.4)$ & $16(80.0)$ & 0.508 \\
\hline $5-9$ & $35(13.8)$ & $2(10.0)$ & 0.633 \\
\hline $10-20$ & $24(9.4)$ & $1(5.0)$ & 0.185 \\
\hline$\geq 20$ & $1(0.4)$ & $1(5.0)$ & 0.011 \\
\hline \multicolumn{4}{|l|}{ Echocardiography } \\
\hline $\operatorname{LVEF}(\%)$ & $63.1 \pm 6.5$ & $63.0 \pm 5.1$ & 0.965 \\
\hline E wave $(\mathrm{m} / \mathrm{s})$ & $0.65 \pm 0.16$ & $0.74 \pm 0.26$ & 0.024 \\
\hline A wave $(\mathrm{m} / \mathrm{s})$ & $0.83 \pm 0.19$ & $0.88 \pm 0.25$ & 0.421 \\
\hline E/A ratio & $0.79 \pm 0.21$ & $0.79 \pm 0.28$ & 0.974 \\
\hline$e^{\prime}(m / s)$ & $0.08 \pm 0.02$ & $0.08 \pm 0.02$ & 0.512 \\
\hline E/e' ratio & $9.2 \pm 2.7$ & $9.8 \pm 3.1$ & 0.347 \\
\hline E/e' ratio > $13(n, \%)$ & $26(10.2)$ & $3(15.0)$ & 0.086 \\
\hline DT $(s)$ & $247.0 \pm 52.8$ & $244.6 \pm 50.7$ & 0.844 \\
\hline LV mass index $\left(\mathrm{g} / \mathrm{m}^{2}\right)$ & $85.6 \pm 19.3$ & $86.9 \pm 15.4$ & 0.735 \\
\hline LV mass index $\left(\mathrm{g} / \mathrm{m}^{1.7}\right)$ & $74.5 \pm 21.1$ & $73.3 \pm 17.2$ & 0.775 \\
\hline LV hypertrophy $(n, \%)^{a}$ & $35(13.8)$ & $1(5.9)$ & 0.354 \\
\hline
\end{tabular}

Italic values indicate significant associations

a LV hypertrophy was defined as LVMi > $115 \mathrm{~g} / \mathrm{m}^{2}$ for males, $>95 \mathrm{~g} / \mathrm{m}^{2}$ for females

\section{Appendix 2}

See Table 6.

Table 6 Multivariate linear regression model for prediction of PHQ-9 score in older asymptomatic T2DM

\begin{tabular}{lcc}
\hline $\begin{array}{l}\text { Chi square } \\
\mathbf{0 . 0 4 3}\end{array}$ & $\mathbf{B}(\mathbf{9 5 \%} \mathbf{C l})$ & p value \\
\hline Age & $-0.04(-5.45,12.08)$ & 0.457 \\
Gender & $-0.97(-2.00,0.05)$ & 0.063 \\
BMl & $0.12(0.03,0.20)$ & 0.009 \\
\hline
\end{tabular}

Italic values indicate significant associations

\section{Appendix 3}

See Fig. 4.

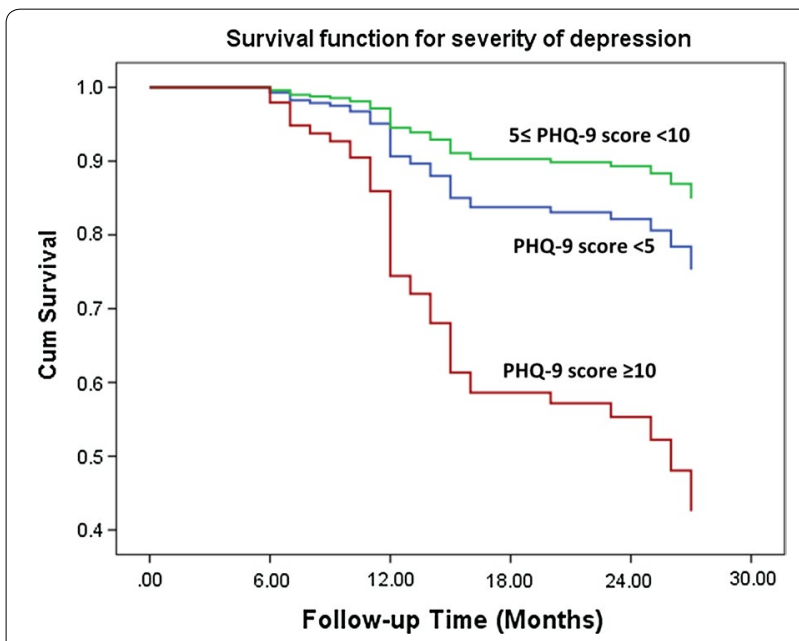

Fig. 4 Cumulative survival of 254 elderly asymptomatic T2DM stratified by severity of depression

\section{Publisher's Note}

Springer Nature remains neutral with regard to jurisdictional claims in published maps and institutional affiliations.

Received: 30 November 2017 Accepted: 16 January 2018

Published online: 24 January 2018

\section{References}

1. Bell DS. Heart failure: the frequent, forgotten, and often fatal complication of diabetes. Diabetes Care. 2003;26:2433-41.

2. Bertoni AG, Hundley WG, Massing MW, Bonds DE, Burke GL, Goff DC Jr. Heart failure prevalence, incidence, and mortality in the elderly with diabetes. Diabetes Care. 2004:27:699-703.

3. Roy T, Lloyd CE. Epidemiology of depression and diabetes: a systematic review. J Affect Disord. 2012;142(Suppl):S8-21.

4. Reeves GC, Alhurani AS, Frazier SK, Watkins JF, Lennie TA, Moser DK. The association of comorbid diabetes mellitus and symptoms of depression 
with all-cause mortality and cardiac rehospitalization in patients with heart failure. BMJ Open Diabetes Res Care. 2015;3:e000077.

5. Abramson J, Berger A, Krumholz HM, Vaccarino V. Depression and risk of heart failure among older persons with isolated systolic hypertension. Arch Intern Med. 2001;161:1725-30.

6. Mancia G, Fagard R, Narkiewicz K, et al. 2013 ESH/ESC guidelines for the management of arterial hypertension: the Task Force for the management of arterial hypertension of the European Society of Hypertension (ESH) and of the European Society of Cardiology (ESC). J Hypertens. 2013;31:1281-357.

7. Kroenke K, Spitzer RL, Williams JB. The PHQ-9: validity of a brief depression severity measure. J Gen Intern Med. 2001;16:606-13.

8. Lang RM, Badano LP, Mor-Avi V, et al. Recommendations for cardiac chamber quantification by echocardiography in adults: an update from the American Society of Echocardiography and the European Association of Cardiovascular Imaging. J Am Soc Echocardiogr. 2015;28(1-39):e14

9. Nagueh SF, Appleton CP, Gillebert TC, et al. Recommendations for the evaluation of left ventricular diastolic function by echocardiography. Eur Heart J Cardiovasc Imaging. 2009;10:165-93.

10. Nagueh SF, Appleton CP, Gillebert TC, et al. Recommendations for the evaluation of left ventricular diastolic function by echocardiography. J Am Soc Echocardiogr. 2009;22:107-33.

11. Ho KK, Pinsky JL, Kannel WB, Levy D. The epidemiology of heart failure: the Framingham Study. J Am Coll Cardiol. 1993;22:6A-13A.

12. Fine JP, Gray RJ. A proportional hazards model for the subdistribution of a competing risk. J Am Stat Assoc. 1999;94:496-509.

13. Gray RJ. A class of K-sample tests for comparing the cumulative incidence of a competing risk. Ann Statist. 1988;16(3):1141-54.

14. Rutledge T, Reis VA, Linke SE, Greenberg BH, Mills PJ. Depression in heart failure. J Am Coll Cardiol. 2006:48:1527-37.

15. Sherwood A, Blumenthal JA, Hinderliter AL, et al. Worsening depressive symptoms are associated with adverse clinical outcomes in patients with heart failure. J Am Coll Cardiol. 2011;57:418-23.

16. Chaudhry SI, McAvay G, Chen S, et al. Risk factors for hospital admission among older persons with newly diagnosed heart failure: findings from the Cardiovascular Health Study. J Am Coll Cardiol. 2013;61:635-42.

17. Jani BD, Mair FS, Roger VL, Weston SA, Jiang R, Chamberlain AM. Comorbid depression and heart failure: a community cohort study. PLoS ONE. 2016;11:e0158570.

18. Faller $\mathrm{H}$, Stork $\mathrm{S}$, Schowalter $\mathrm{M}$, et al. Depression and survival in chronic heart failure: does gender play a role? Eur J Heart Fail. 2007;9:1018-23.

19. Gustad LT, Laugsand LE, Janszky I, Dalen H, Bjerkeset O. Symptoms of anxiety and depression and risk of heart failure: the HUNT Study. Eur J Heart Fail. 2014:16:861-70

20. Williams SA, KasI SV, Heiat A, Abramson JL, Krumholz HM, Vaccarino V. Depression and risk of heart failure among the elderly: a prospective community-based study. Psychosom Med. 2002;64:6-12.

21. Ogilvie RP, Everson-Rose SA, Longstreth WT Jr, Rodriguez CJ, Diez-Roux AV, Lutsey PL. Psychosocial factors and risk of incident heart failure: the multi-ethnic study of atherosclerosis. Circ Heart Fail. 2016;9:e002243.

22. Fiore V, Marci M, Poggi A, et al. The association between diabetes and depression: a very disabling condition. Endocrine. 2015;48:14-24.

23. Semenkovich K, Brown ME, Svrakic DM, Lustman PJ. Depression in type 2 diabetes mellitus: prevalence, impact, and treatment. Drugs. 2015;75:577-87.
24. Lustman PJ, Griffith LS, Freedland KE, Clouse RE. The course of major depression in diabetes. Gen Hosp Psychiatry. 1997;19:138-43.

25. Coleman SM, Katon W, Lin E, Von Korff M. Depression and death in diabetes; 10-year follow-up of all-cause and cause-specific mortality in a diabetic cohort. Psychosomatics. 2013;54:428-36.

26. Yang H, Wang Y, Nolan M, Negishi K, Okin PM, Marwick TH. Community screening for nonischemic cardiomyopathy in asymptomatic subjects $\geq 65$ years with stage B heart failure. Am J Cardiol. 2016;117:1959-65.

27. Dandamudi S, Slusser J, Mahoney DW, Redfield MM, Rodeheffer RJ, Chen $\mathrm{HH}$. The prevalence of diabetic cardiomyopathy: a population-based study in Olmsted County, Minnesota. J Card Fail. 2014:20:304-9.

28. Yang H, Wang Y, Negishi K, Nolan M, Marwick TH. Pathophysiological effects of different risk factors for heart failure. Open Heart. 2016;3:e000339.

29. Suto M, Tanaka H, Mochizuki Y, et al. Impact of overweight on left ventricular function in type 2 diabetes mellitus. Cardiovasc Diabetol. 2017;16:145.

30. Joynt KE, Whellan DJ, O'Connor CM. Why is depression bad for the failing heart? A review of the mechanistic relationship between depression and heart failure. J Card Fail. 2004:10:258-71.

31. Singh P, Khullar S, Singh M, Kaur G, Mastana S. Diabetes to cardiovascular disease: is depression the potential missing link? Med Hypotheses. 2015;84:370-8.

32. Joynt KE, Whellan DJ, O'Connor CM. Depression and cardiovascular disease: mechanisms of interaction. Biol Psychiatry. 2003;54:248-61.

33. Carr ME. Diabetes mellitus: a hypercoagulable state. J Diabetes Complicat. 2001;15:44-54.

34. Pickup JC, Crook MA. Is type II diabetes mellitus a disease of the innate immune system? Diabetologia. 1998:41:1241-8.

35. Michalsen A, Konig G, Thimme W. Preventable causative factors leading to hospital admission with decompensated heart failure. Heart. 1998;80:437-41.

36. Baldassarre S, Fragapani S, Panero A, et al. NTproBNP in insulin-resistance mediated conditions: overweight/obesity, metabolic syndrome and diabetes. The population-based Casale Monferrato Study. Cardiovasc Diabetol. 2017;16:119.

37. Lichtman JH, Bigger JT Jr, Blumenthal JA, et al. Depression and coronary heart disease: recommendations for screening, referral, and treatment: a science advisory from the American Heart Association Prevention Committee of the Council on Cardiovascular Nursing, Council on Clinical Cardiology, Council on Epidemiology and Prevention, and Interdisciplinary Council on Quality of Care and Outcomes Research: endorsed by the American Psychiatric Association. Circulation. 2008;1 18:1768-75.

38. Elderon L, Smolderen KG, Na B, Whooley MA. Accuracy and prognostic value of American Heart Association: recommended depression screening in patients with coronary heart disease: data from the Heart and Soul Study. Circ Cardiovasc Q Outcomes. 2011;4:533-40.

39. Siddiqui S. Depression in type 2 diabetes mellitus - a brief review. Diabetes Metab Syndr. 2014;8:62-5.

\section{Submit your next manuscript to BioMed Central and we will help you at every step:}

- We accept pre-submission inquiries

- Our selector tool helps you to find the most relevant journal

- We provide round the clock customer support

- Convenient online submission

- Thorough peer review

- Inclusion in PubMed and all major indexing services

- Maximum visibility for your research

Submit your manuscript at www.biomedcentral.com/submit
(O) BioMed Central 